Ophthalmologe 2011 - 108:310

DOI 10.1007/s00347-011-2359-0

(c) Springer-Verlag 2011

\section{Friedburg \\ Krefeld}

\title{
Nachruf auf Professor Dr. Hans-Kunibert Krause
}

Professor Dr. Hans-Kunibert Krause, der Autor des Leitthemenbeitrags „Fallstricke bei der Bestimmung von Nahbrillen", starb plötzlich und unerwartet am 30.12.2010.

Hans-Kunibert Krause wurde am 23.03.1947 in Castrop-Rauxel geboren, wo sein Vater als Allgemeinarzt tätig war. Er studierte Physik in Münster und Bochum, erlangte sein Diplom 1973 und promovierte zum Dr. rer. nat. an der RuhrUniversität Bochum im Bereich Plasmaphysik. Er arbeitet ab 1980 an der Augenklinik der Universität Münster und habilitierte sich dort für das Fach Ophthalmologische Optik am 12.02.1987.

$\mathrm{Ab} 1984$ arbeitete und lehrte Herr PD Dr. Krause als Akademischer Rat und ab 1989 als Akademischer Oberrat an der Augenklinik der Universität Münster. Im Jahr 1993 wurde er zum apl. Professor ernannt. Mit seinen Veröffentlichungen in Fachzeitschriften, Büchern und Buchbeiträgen über ophthalmologische Optik so-

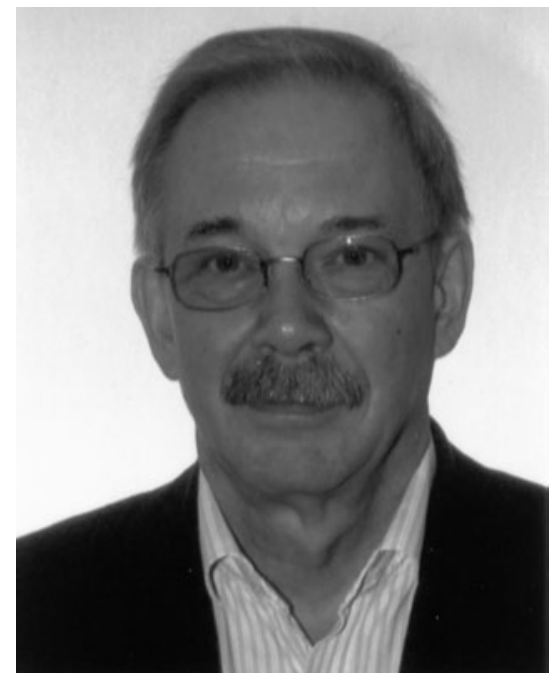

Professor Dr. Hans-Kunibert Krause, 1947-2010 wie seinen Vorträgen auf Kongressen gewann er bald Freunde unter den Augenärzten und wurde fortan als Kapazität im Bereich ophthalmologische Optik geachtet. Hierbei spielte sicher auch sein lebendiger, humorvoller Vortragsstil eine wesentliche Rolle. Seine Beiträge waren aus augenärztlichen Fortbildungsveranstaltungen nicht mehr wegzudenken und haben vielen Augenärzten den Weg in die Refraktionstätigkeit geebnet.

Zum 01.03.2002 wechselte Herr Professor Dr. Krause an die Hochschule Aalen Studiengang Augenoptik und Hörakustik, behielt aber sein Engagement in der Fortbildung der Augenärzte bei. Der vorliegende Beitrag „Fallstricke bei der Bestimmung von Nahbrillen" wurde kurz vor seinem Tod fertiggestellt und ist so sein Vermächtnis für uns Augenärzte.

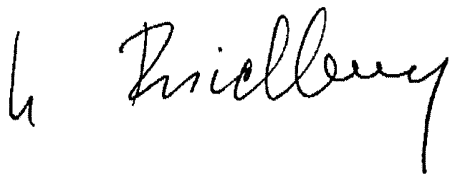

\section{Korrespondenzadresse}

Prof. Dr. D. Friedburg

Carl-Schurz-Str. 9, 47803 Krefeld

friedburgkr@arcor.de 